\title{
Walk them or No leg to stand on! \\ Diagnostic delay of neurologic conditions in young children
}

\author{
Amanda Stock ${ }^{1}$, Karen Dunn ${ }^{1}$, John A Cheek ${ }^{1,2}$ \\ 1 .Emergency Department \\ Royal Children's Hospital \\ Melbourne, Australia \\ 2. Emergency Department \\ Monash Medical Centre \\ Melbourne,Australia \\ Introduction
}

Delay in the diagnosis of uncommon neurologic conditions is unfortunately common in paediatrics, particularly in very young children. The symptoms of neurologic conditions can be non-specific and the signs on examination can be difficult to elicit. Furthermore, symptoms such as lethargy, poor appetite, and decreased interest in playing may be easily rationalised to common conditions such as viral infections. The challenge in paediatric acute care is the detection of low-incidence, serious neurological conditions amongst the ubiquitous upper respiratory tract infections (URTI) and viral infections which can account for $9.5 \%$ of ED presentations. ${ }^{1}$

The ability to walk can provide many clues to the well-being of a child, however, getting a child to walk is not always part of the routine examination of children in the Emergency Department(ED). Why don't we walk children? Young children may be carried to the cubicle by their parents and then placed on the bed so we overlook the fact that they cannot walk. The child may be fractious, sleepy, or uncooperative and we don't want to impose upon them and prefer to let sleeping children lie. By not walking the child important clues may be missed. We present three cases to illustrate this point and highlight the importance of walking children who are usually ambulant.

Case 1

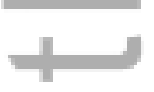

Age 2 years $9 m$ ths - Triage category 4

Presenting complaint to triage: "Two days unwell with lethargy, raspy breathing, drooling and not talking. Parents concerned about quiet behaviour. Having hydralyte in triage and feeding well. Quiet, clingy to dad."

This is the author manuscript accepted for publication and has undergone full peer review but has not been through the copyediting, typesetting, pagination and proofreading process, which may lead to differences between this version and the Version of Record. Please cite this article as doi: $10.1111 / 1742-6723.12585$

This article is protected by copyright. All rights reserved. 
The patient had been treated for a chest infection with amoxycillin/clavulanic acid 9 days prior to presentation. His respiratory symptoms improved and two days before being seen in the ED he became lethargic and unsettled. The day after this lethargy developed he was assessed at another paediatric ED and was diagnosed with a viral illness and discharged home. The parents reported that he needed to be carried around and there was no documentation of his ability to walk. On the day of presentation he was afebrile and was noted to be irritable and lethargic at times. His heart rate was 80 when asleep.The examination was confined to his cardiorespiratory, abdominal and ENT systems. There was no record of a neurological examination. Full blood count (FBC) and C reactive protein (CRP) were normal. The working diagnosis was viral infection and the child was admitted to hospital with a view to possible lumbar puncture and observation. During the emergency consultant ward round he was reexamined and found to be unable to weight bare, had truncal ataxia and upper motor neuron signs in the lower limbs.

He had underwent an urgent MRI which showed features consistent with Acute Demyelinating Encephalomyelitis (ADEM).

Case 2

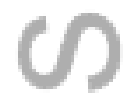

2 years $9 \mathrm{mth}$ - Triage category 3

Presenting complaint to triage: "Decreased oral intake last three days, now lethargic and refusing to walk. Mum tried to give hydralyte via a syringe but refusing to drink. Lethargic in mum's arms."

The patient had a four day history of fever, coryza, sore throat and lethargy. On the day of presentation he was unable to drink fluids. He was afebrile and examination was limited to cardiorespiratory, abdominal and ENT system. There was no neurological examination documented. A diagnosis of URTI with moderate dehydration was made and the child was admitted for rapid nasogastric rehydration to the ED observation unit. On review the following morning the parents reported that he had been complaining of sore legs for the past few days and was unable to weight bare when he stood up. Examination revealed absent lower limb reflexes and $3 / 5$ power, bilateral facial weakness and an absent gag reflex.

He was referred to the neurology unit where he underwent nerve conduction studies which confirmed the clinical diagnosis of Guillain-Barre Syndrome.

Case 3

2 year old

The patient presented to ED three times in the five days prior to diagnosis. The history was of intermittent fever, vomiting and poor intake. The diagnosis on the three prior occasions was viral infection. 
First presentation: Triage Category 3, "Fever on and off the last week, lethargic at home, vomiting this am."

Second presentation: Triage Category 4, "Lethargy, not wanting to walk, seems unsteady."

Third presentation: Triage Category 3, "Fever, recently diagnosed viral illness, very miserable, difficulty walking."

On each occasion the examination focused on cardiorespiratory, abdominal and ENT systems. There was no neurological examination of the lower limbs documented. Over the three presentations urine microscopy, nasal swab, FBC and CRP were performed and were normal.

On the fourth presentation two days after the third, the child was encephalopathic and had posturing of the upper and lower limbs. She was intubated and treated with broad-spectrum antibiotics.

An MRI showed features consistent with ADEM.

\section{Discussion}

There are many lessons to learn from these three cases. While it is easy to be critical of the delay in diagnosis, the children presented in different time periods, and were seen by different doctors. However, they had elements in common. They were (i) young; (ii)irritable; (iii) were easily carried by the parent; (iv) did not have a neurologic examination performed; (v) no documentation of their ability to walk despite the triage nurse documenting concerns about walking in two patients; and (vi) there was a presumption of a viral illness.

The ability to walk is an important milestone in a child's life. If the presentation is purely one of not wanting to walk the diagnostic approach is quite straight forward with a search for common causes such as fractures, synovitis of the hip or a foreign body in the foot. However, when the predominant symptoms do not relate to walking this key feature may be overlooked. Cognitive bias, rationalising the behaviour to an underlying illness such as a virus , may lead to diagnostic fixation and incomplete examination.

Detailed neurological examination in the preschool child is a challenging and time consuming skill which requires patience to perform. An uncooperative child can make appreciation of ataxia, facial palsies and visual problems, difficult 2 . It would be impractical to perform a detailed neurologic examination on every child with nonspecific symptoms in the ED, however, examining a child's gait is simple, quick, and provides a wealth of information that can direct the need for further examination of the neurological system.

In a retrospective review of 23 pre-schoolers with GBS, $65 \%$ had the presenting complaint of inability to walk and leg pain ${ }^{3}$.These symptoms may not be appreciated due to pain being poorly localised and the lack of a verbal ability to describe pain. Two-thirds of these preschoolers were misdiagnosed with conditions such as tonsillitis, myopathy and discitis and a quarter had time to diagnosis of more than one week. This delay in treatment can lead to adverse outcomes given that $15-20 \%$ of children with GBS require respiratory support 4 . GBS 
can also risk being misdiagnosed as an URTI as bulbar dysfunction and the resulting difficulty swallowing and drinking may be ascribed to a sore throat or an URTI.

It is understandable that conditions like ADEM and GBS are misdiagnosed as infectious diseases. In a review of patients with ADEM, 93\% had fever, cough, rhinorrhea, vomiting or diarrhoea in the three weeks prior to presentation and a quarter were febrile on admissions. Infectious diseases are more common and the clinician is trained to avoid missing a diagnosis of serious bacterial infection. There is a risk that when inflammatory markers are tested and the result is normal that the clinician is falsely reassured.

We are accustomed to seeing pre-schoolers pushed in strollers or carried by caregivers in the community. Therefore it follows that observing them in ED being carried or pushed may not afford the clinician the same visual cues compared to an older child being brought in the same way. An older child is also more likely to be able to describe their symptoms and examination is easier.

When children are miserable, uncooperative or sleeping it may feel like an imposition to make a child walk and we may fear upsetting parents. If parents understand why we need to observe their child walking and it is performed in a sensitive way then this may lessen the distress. In the age of smart phones it can be useful for a parent to film the walking while the clinician observes so that other clinicians can see it.

In the adult world being "off your feet" is a red flag. Equally, a normally ambulant child in whom there is a history of not walking or refusing to walk should also be considered a red flag and should trigger a detailed neurological examination and broader differential diagnosis.

We recommend that clinicians ensure that watching a child walk is as much a part of every clinical examination as auscultating the chest. This will ensure that neurological conditions with low prevalence are more likely to be expeditiously diagnosed.

\section{References}

1. Acworth J, Babl F, Borland M, et al.Patterns of presentation to the Australian and New Zealand Paediatric Emergency Research Network. Emerg Med Australas. $2009 ; 21: 59-66$

2. Steinlin M, Mackay MT. Emergency management of ischemic stroke in children. -Curr Treat Options Neurol. 2015 ;17:349

3. Roodbol J, de Wit MC, Walgaard C, et al. Recognizing Guillain-Barré syndrome in preschool children. Neurology 2011; 76:807-810

4. $\mathrm{Hu} \mathrm{MH}$, Chen $\mathrm{CM}$, Lin $\mathrm{KL}$, et al. Risk factors of respiratory failure in children with Guillain-Barre syndrome. Pediatr Neonatol 2012; 53:295-299 
5. John A. D. Leake, MD, MPH; Salvatore Albani, MD et al Acute Disseminated Encephalomyelitis in Childhood: Epidemiologic, Clinical and Laboratory Features.Pediatr Infect Dis J 2004;23(8)

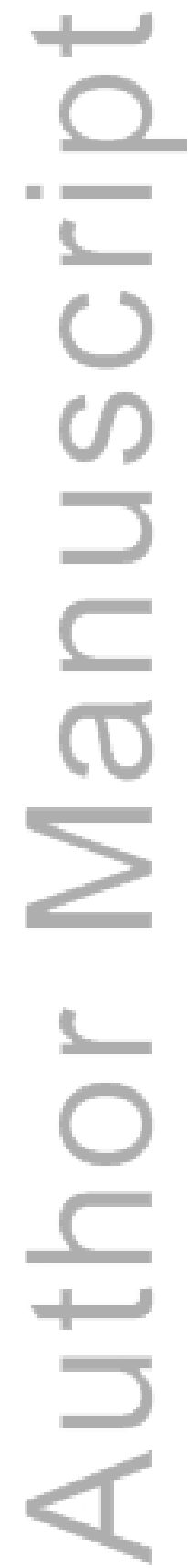

This article is protected by copyright. All rights reserved. 


\section{University Library}

\section{- M M N E R VA A gateway to Melbourne's research publications}

Minerva Access is the Institutional Repository of The University of Melbourne

Author/s:

Stock, A;Dunn, K;Cheek, JA

Title:

Walk them or no leg to stand on! Diagnostic delay of neurologic conditions in young children

Date:

2016-10-01

Citation:

Stock, A., Dunn, K. \& Cheek, J. A. (2016). Walk them or no leg to stand on! Diagnostic delay of neurologic conditions in young children. EMERGENCY MEDICINE AUSTRALASIA, 28 (5), pp.600-602. https://doi.org/10.1111/1742-6723.12585.

Persistent Link:

http://hdl.handle.net/11343/291338 